\title{
Effect of Leaf Positions on Total Phenolics, Flavonoids and Proantho- cyanidins Content and Antioxidant Activities in Lantana Camara (L)
}

\author{
Dipita Bhakta and Deepak Ganjewala ${ }^{1}$ \\ School of Biotechnology, Chemical and Biomedical Engineering, VIT University, \\ Vellore-632 014 (T. N.), India
}

Received 20 January 2009, accepted in revised form 9 April 2009

\begin{abstract}
Changes in the level of phenolics, flavonoids and proanthocyanidins with leaf positions were studied in L. camara twigs. Leaves at different positions (from apex to base) in a twig represented gradient increase in the leaf age, apical being the youngest leaves. The study showed that the fresh weight, dry weight and area of the leaves increased rapidly from I until IV position in a twig. Levels of phenolics remained unchanged from I to V leaf position, while a sharp increase in the levels of proanthocyanidins and flavonoids was observed during I to III leaf position which decreased markedly thereafter. At any leaf position in a twig, the level of proanthocynidin was higher than both phenolics and flavonoids, while the proportion of flavonoids was much higher than the phenolics. In fact, phenolics were present in very small amounts. In addition, antioxidant potential of leaves extracts was measured in terms of reducing and scavenging activity. The study revealed that extracts prepared from leaves present from I to III position exhibited significantly higher antioxidant activities than the leaves present from IV to V position. The study thus revealed that leaf positions (age) influence the level of secondary metabolites and thereby their antioxidant properties.
\end{abstract}

Keywords: Antioxidant; Flavonoids; Lantana camara; Phenolics; Proanthocynidins.

C) 2009 JSR Publications. ISSN: 2070-0237 (Print); 2070-0245 (Online). All rights reserved.

DOI: 10.3329 /jsr.v1i2.1873

\section{Introduction}

The genus Lantana contains seven species, six from South America and one from Ethiopia [1]. Lantana camara (L) commonly known as wild or red sage, is an evergreen aromatic shrub, grows up to a height of 1-2 m, occurs luxuriously in elevations up to $2000 \mathrm{~m}$ in tropical, sub tropical and temperate regions [2]. Since very long time L. camara is reported to be used in traditional medicine system for the treatment of itches, cuts, ulcers, swellings, bilious fever, cataract, eczema and rheumatism. Various parts of the plants are used in the treatment of cold, headache, uterine haemorrhage, chicken pox, eye injuries, whooping cough, asthma [3], bronchitis and arterial hypertension [4, 5]. Lancamarone, a steroid from the leaves possess cardio tonic properties, while Lantamine an alkaloid from

\footnotetext{
${ }^{1}$ Corresponding author: deepakganjawala73@yahoo.com
} 
the bark of stems and roots show strong antipyretic and antispasmodic properties comparable with those of quinine [6]. The leaf oil is used as an antiseptic for wounds. The roots are used for the treatment of tooth ache and the flowers for chest complaints in children [7]. Pharmacological investigations indicated that extracts of shoots of Lantana camara (L) exhibited antibacterial properties. Recently, Verma and Verma [8] have reported the termiticidal activity of Lantana camara var. aculeata leaves. Earlier, we studied the biochemical compositions and antibacterial activity of different L. camara plants with red, white, yellow and lavender flowers (personal communication).

Previously, L. camara has been extensively investigated for the phytochemical compositions. Triterpenes (Lantadene type), steroids and alkaloids are reported as major phytochemical constituents of L. camara [9-13]. However, published reports on leaf essential oil compositions have reported the high content of sesquiterpenes with mainly $\beta$ caryophyllene [13- 15], zingiberene, arcurcumene [15], gemacrene-D, bisabolene [16], $\delta$ humulene $[13,17]$ derivatives up to $65 \%$ as major essential oil constituents. Although several reports are available in literature concerning phytochemical investigations and biological activities of L. camara, reports on accumulation of secondary metabolites such as phenolics, flavonoids and proanthocyanidins in leaves and their antioxidant activities has not yet been studied sufficiently. Nevertheless, few reports published previously described geographic variation in essential oils of Lantana camara leaves and flowers. The primary aim of the present study was to investigate accumulation pattern of secondary metabolites of antioxidant properties in successive leaves in L. camara twig.

\section{Materials and Methods}

\subsection{Plant materials}

Twigs were cut from matured Lantana camara (L.) plants grown in campus of the Vellore Institute of Technology (VIT) University, Vellore, Tamil Nadu during February to April 2008. Leaves present at different nodal position (from apical to basal part of the twig) representing gradient increase in age were used for the study. Leaves in a twig were numbered from I (apical) to $\mathrm{V}$ leaf (basal) which represented a gradient increase in age, the first (I) leaf being a youngest one (Fig. 1)

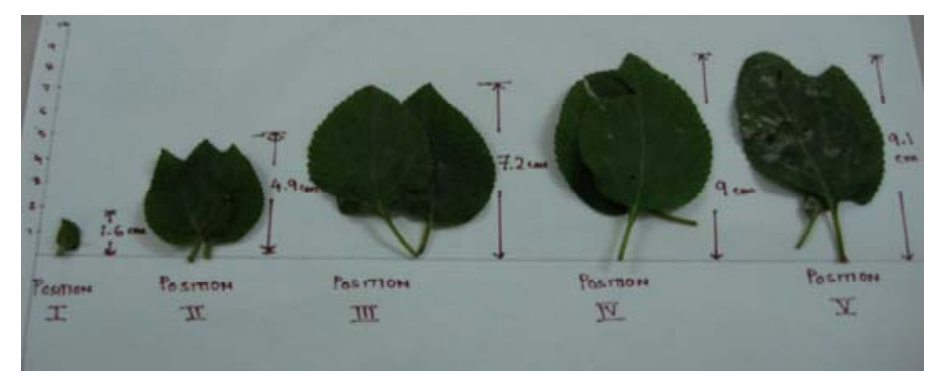

Fig. 1. Lantana camara (L.) leaves (I to V) representing gradient increase in leaf age and area. 


\subsection{Determination of Fresh and Dry Weight}

Leaves were detached from different positions counted and weighed for determining the fresh weight. A known numbers of leaves were also kept for drying in an oven at $40^{\circ} \mathrm{C}$ to $50^{\circ} \mathrm{C}$ till constant weight was obtained for the determination of the dry weight.

\subsection{Extraction and estimation of phenolics, proanthocyanidins and flavonoids}

For extraction of phenolics $1 \mathrm{~g}$ of leaf powder was extracted for 10 hours with $10 \mathrm{ml} 0.3$ $\mathrm{M} \mathrm{HCl}$ in methanol. The extract thus obtained was centrifuged at $3000 \mathrm{rpm}$ for 15 minutes to obtain the supernatant rich in phenolics. The residue left over from the first extract was once again washed with $10 \mathrm{ml}$ of $0.3 \mathrm{M} \mathrm{HCl}$ and the washing was pooled to the supernatant which was kept for evaporation to remove the solvent. The dried extract was stored in fridge till it was used for estimation. The dried phenolics extract was dissolved in $5 \mathrm{ml}$ of distilled water and $0.1 \mathrm{ml}$ of each of the test extract was taken. The volume was made up to $7 \mathrm{ml}$ in each test tube using distilled water. $0.5 \mathrm{ml}$ of Folin-Ciocalteau was added to each of the tube and shaken for 3 minutes. $1 \mathrm{ml}$ of $35 \%$ sodium carbonate was added and the tubes were allowed to stand for one hour. The deep blue coloration developed was read for absorbance at $630 \mathrm{~nm}$. The concentration of phenolics in the test extract was calculated using standard tannic acid $(1 \mathrm{mg} / \mathrm{ml})$ curve.

For the extraction of flavonoids and proanthocyanidins $2.5 \mathrm{~g}$ of the dried leaf powder was extracted for 24 hours with $30 \mathrm{ml}$ of methanol in glass conical flask using a shaker at $25^{\circ} \mathrm{C}$ and filtered thereafter. The residue was again extracted twice with $5 \mathrm{ml}$ of methanol. The pooled methanol extracts were used for the estimation of the flavonoids and proanthocyanidins. Flavonoids content was measured using a modified colorimetric method [18]. Proanthocyanidins was determined by the procedure of Sun et al. [19].

\subsection{Phytochemical analysis}

Specific qualitative tests were conducted to investigate the presence of various secondary metabolites in the leaves and flowers of Lantana camara (L) as described previously [20].

\subsection{Antioxidant Activity}

Antioxidant activity was measured in terms of reducing power and DPPH radical scavenging activity. The reducing power of the extracts obtained from leaves of different positions L. camara twig were determined according to the method of Oyaizu [21]. The free radical (DPPH radical) scavenging activity was determined by the method of Shimada et al. [22] and Yang et al. [23].

Scavenging activity $(\%)=[($ Abs at $517 \mathrm{~nm}$ of control - Abs at $517 \mathrm{~nm}$ of sample $) / \mathrm{Abs}$ at $517 \mathrm{~nm}$ of control] $\times 100$. 


\section{Results and Discussion}

\subsection{Changes in physiological parameters}

Physiological parameters such as leaf area $\left(\mathrm{cm}^{2}\right)$, fresh and dry weight (gram) rapidly increased from leaf position I to III in a twig which remained constant in IV leaf position onward (Table 1). These results suggested that leaves from position I to III grows rapidly, hence most active in biosynthesis and accumulation of secondary metabolites such as phenolics and flavonoids. The decline in the fresh and dry weights of the leaves in the later leaf position (IV leaf onwards) however indicated beginning of leaf senescence. These developmental changes in terms of fresh and dry weight are most common physiological parameters and have been reported from a number of plants.

Table 1. Changes in the leaf growth parameters viz., area, fresh weight and dry weight of I to V leaves of the Lantana camara (L.).

\begin{tabular}{ccccc}
\hline $\begin{array}{c}\text { Leaf } \\
\text { Position }\end{array}$ & \multicolumn{4}{c}{ Growth parameters } \\
\cline { 2 - 5 } & $\begin{array}{c}\text { Leaf area } \\
\left(\mathrm{cm}^{2}\right)\end{array}$ & $\begin{array}{c}\text { Fresh } \\
\text { weight }(\mathrm{g})\end{array}$ & Dry weight $(\mathrm{g})$ & $\begin{array}{c}\text { Leaf expansion } \\
(\%)\end{array}$ \\
\hline I & 1.6 & 12.5 & 5.0 & 18 \\
II & 4.9 & 36 & 13.8 & 54 \\
III & 7.2 & 50 & 19.8 & 79 \\
IV & 9.0 & 42.8 & 18.8 & 99 \\
V & 9.1 & 40.5 & 19.7 & 100 \\
\hline
\end{tabular}

\subsection{Total phenolics, flavonoids and proanthocynidines content and their Antioxidant properties}

Level of three secondary metabolites such as phenolics, flavonoids and proanthocyanidins were measured in leaves from I (apical) to $\mathrm{V}$ (basal) position in a twig (Table 2). Flavonoids and proanthocyanidins were expressed respectively as quercetin $(\mu \mathrm{g} / \mathrm{ml})$ and catechin $(\mathrm{mg} / \mathrm{ml})$ equivalent. The results showed that the levels of phenolics and flavonoids $(\mu \mathrm{g} / \mathrm{ml})$ were very less in comparison to that of proanthocyanidins $(\mathrm{mg} / \mathrm{ml})$. The levels of both flavonoids and proanthocynidines increased rapidly in premature leaves, from I to III position in a twig. The flavonoids content which was around 10.7 $(\mu \mathrm{g} / \mathrm{ml})$ in leaves at I position increased substantially up to $21.7 \mu \mathrm{g} / \mathrm{ml}$ in leaves at III position. Similarly, proanthocynidines content $(\mathrm{mg} / \mathrm{ml})$ reached to maximum level of 181.6 in leaves at III position from the level of 132.5 in leaves at I position. However, levels of both flavonoids and proanthocynidines decreased in leaves present thereafter. Phenolics content remained almost unchanged in leaves from position I to V (Table 2). Phytochemical investigations of leaves extracts revealed the presence of secondary metabolites viz., alkaloids, terpenoids, phenolics, tannins, glycosides, saponins and phytosterols in leaves from I to $\mathrm{V}$ position in a twig. The variation observed in the levels 
of phenolics, flavonoids and proanthocyanidins in leaves extracts could be mainly due to the differences in developmental ages of the leaves present at different positions. Beside this, seasonal, genetic, and agronomic factors also affect the level of phenolics [24, 25].

\subsection{Antioxidant properties of phenolics, flavonoids and proanthocynidines}

Results of antioxidant assay performed are presented in Table 2. Antioxidant potential in terms of reducing activity exhibited by leaves methanol extract was virtually very less except the extracts of leaves obtained from III position. Similarly, the free radical scavenging activity of leaves extracts measured using DPPH showed that leaves extracts of I to $\mathrm{V}$ position had substantial free radical scavenging activity. The reducing power has been used as one of important antioxidant capability for medicinal herbs [26, 27] while DPPH changes its color from violet to yellow when it is reduced, the reaction which has been considered as antioxidants and therefore radical scavengers [28]. Antioxidant nature of the phenolics has been well documented in a number of plants [23, 29-30]. The key role of phenolics compounds as scavengers of free radicals is emphasized in several previously published reports [30-32]. Likely, proanthocyanidines, a type of flavonoid is known for its high antioxidant properties [33]. The antioxidant activity of the L. camara leaves reported here thus can be mainly attributed to the phenolics and proanthocynidines, unlike the phenolics which has been often responsible for antioxidant properties. The results also indicated that antioxidant activity of leaves decreased from IV to V leaf with decrease in amount of proanthocyanidins. In conclusion, premature leaves (I to III position) in a twig are most active in biosynthesis and accumulation of secondary metabolites, hence exhibits potential antioxidant activity. However, older leaves had less antioxidant activity indicating loss of secondary metabolites as result of leaf senescence.

Table 2. Total phenolics, flavonoids and proanthocyanidins contents and their antioxidant activities in leaves from I to V position in Lantana camara (L.) twig.

\begin{tabular}{|c|c|c|c|c|c|}
\hline \multirow{2}{*}{$\begin{array}{c}\text { Leaf } \\
\text { position }\end{array}$} & \multirow{2}{*}{$\begin{array}{l}\text { Phenolics } \\
(\mu \mathrm{g} / \mathrm{ml})\end{array}$} & \multirow{2}{*}{$\begin{array}{l}\text { Flavonoids } \\
(\mu \mathrm{g} / \mathrm{ml})\end{array}$} & \multirow{2}{*}{$\begin{array}{c}\text { Proanthoc } \\
\text { yanidins } \\
(\mathrm{mg} / \mathrm{ml})\end{array}$} & \multicolumn{2}{|c|}{ Antioxidant activity } \\
\hline & & & & $\begin{array}{c}\text { Reducing } \\
\text { activity } \\
\text { (O.D.) }\end{array}$ & $\begin{array}{c}\% \text { DPPH } \\
\text { scavenging } \\
\text { activity }\end{array}$ \\
\hline I & 0.036 & 10.7 & 132.5 & 0.021 & 57.5 \\
\hline II & 0.037 & 16.0 & 136.3 & 0.021 & 61 \\
\hline III & 0.038 & 21.7 & 181.6 & 0.041 & 62 \\
\hline IV & 0.036 & 8.2 & 119.3 & 0.015 & 55 \\
\hline $\mathrm{V}$ & 0.035 & 6.9 & 102.4 & 0.026 & 54 \\
\hline
\end{tabular}

\section{Conclusion}

For the first time we report here the effect of leaf position (age) on the accumulation of secondary metabolites viz., phenolics, proanthocyanidins and flavonoids in L. camara. The study revealed that younger leaves (I to III position) are most active in biosynthesis 
and accumulation of these secondary metabolites than the matured leaves (IV to $\mathrm{V}$ position). Also, their antioxidant activities vary with secondary metabolites content and compositions. Younger leaves extracts had strong antioxidant activity than the older or matured leaves. In conclusion, leaf ontogeny affects the biosynthesis and accumulation of secondary metabolites and thereby their biological properties. Currently, developmental studies of the biosynthesis and accumulation of these secondary metabolites is being carried out to demonstrate that different leaf developmental stages also mimics the similar changes in secondary metabolites those observed in different leaf positions.

\section{References}

1. A. A. Munir and J. Adel, Bot. Gard. 17, 1 (1996).

2. O. P. S. Sharma, S. H. P. Makkar, and R. K. Dawra, Toxicon. 26, 975 (1988). doi:10.1016/0041-0101(88)90196-1

3. I. A. Ross, Medicinal plants of the world (Humana Press, New Jersey, 1999).

4. R. P. Rastogi and B. N. Mehrotra, Compendium of Indian medicinal plants, Vol. I, (Central Drug Research Institute, New Delhi, Lucknow and Publication and Information Directorate, CSIR, 1995).

5. R. N. Chopra, I. C. Chopra, and B. S Verma, Supplement to the glossary of Indian Medicinal plants (New Delhi: Publication and information Directorate, CSIR, 1962).

6. B. S. Siddiqui, S. M. Raza, S. Begum, S. Siddiqui, and S. Firdous, Phytochemistry. 38, 681 (1995). doi:10.1016/0031-9422(94)00691-L

7. K. R. Kirtikar and B. D. Basu, Indian Medicinal Plants, Vol. II (1981).

8. R. K. Verma and S. K. Verma, Fitoterapia 77, 466 (2006). doi:10.1016/j.fitote.2006.05.014

9. D. H. R. Barton, P. Demayo, and J. C. Orr, A. J. Chem. Soc. XXXIII , 4160 (1956).

10. A. K Barua, P. Chakrabarti, P. K. Sariyal, and B. C. Das. J. Indian Chem. Soc. 46, 100 (1969).

11. A. K. Barua, P. Chakrabarti, P. K. Sanyal, K. Basu, and K. Nag. J. Indian Chem. Soc. 49, 1063 (1972).

12. A. Sharaf and M. Naguib, Pharm. Bull. 41, 931 (1959).

13. L. Peyron, M. Broua, and M. Rouband, Cosm. Sav. France 2, 205 (1972).

14. T. Mollenbeck, P. Konig, W. Schreier, J. Schaw, Rajanarivony, and L.Ranarivelo, Flav. Fragr. J. 12, 63 (1997).

15. M. B. Ngassoum, Flav. Fragr. J. 14, 208 (1999). doi:10.1002/(SICI) 1099-1026(199907/08)14:4<245::AID-FFJ819>3.0.CO;2-X

16. S. Andersson, J. Chem. Eco. 29, 2319 (2003). doi:10.1023/A:1026278531806

17. M. Saleh, Planta Med. 25, 373 (1974). doi:10.1055/s-0028-1097957

18. Z. Jia and M. Tang, J. Food Chem. 64, 553 (1999).

19. B. S. Sun, J. M. Ricardo Da Silva, and M. I. Spranger, J. Agri. Food Chem. 46, 4267 (1998). doi:10.1021/jf980366j

20. K. Priya and D. Ganjewala, Research J. Phytochemistry 1, 61 (2007). doi:10.3923/rjphyto.2007.61.67

21. M. Oyaizu, Shokehin Kogyo Gakkaishi 35, 771 (1988).

22. K. Shimada, K. Fujikawa, K. Yahara, and T. Nakamura, J. Agri. Food Chem. 40, 945 (1992). doi:10.1021/jf00018a005

23. B. Yang, J. S. Wang, M. M. Zhao, Y. Liu, W. Guang,and Y.M. Jiang, Carb. Res. 341, 634 (2006). doi:10.1016/j.carres.2006.01.004

24. P. J. Hilton and R. Palmer-Jones, J. Sci. Food Agric. 24, 813 (1973). doi:10.1002/jsfa. 2740240709

25. W. Zheng and S.Y. Wang, J. Agric. Food Chem. 49, 4977 (2001). doi:10.1021/jf010697n

26. P. D. Duh, Y.Y. Tu, and G. C. Yen, Lebensmittel-Wissenschaft und-Technologie 32, 269 (1999).

27. P. D. Duh and G. C. Yen, Food Chem. 60, 639 (1997). doi:10.1016/S0308-8146(97)00049-6 
28. W. Brand-Williams, M. Cuvelier, and C. Berset, Lebensmittel-Wissenschaftund-Technologie 28, 25 (1995).

29. M. Naczk and F. Shahidi, J. Chromatograpgy A 1054, 95 (2006).

30. T. Bektas and A. Sokmen, Bioresource Tech. 98, 3076 (2006).

31. J. K. S. Moller, H. L. Madsen, T. Altonen, and L.H. Skibsted, Food Chem. 64, 215 (1999). doi:10.1016/S0308-8146(98)00143-5

32. H. L. Madsen, B. R. Nielsen, G. Bertelsen, and L.H. Skibsted, Food Chem. 57, 331 (1996). doi:10.1016/0308-8146(95)00248-0

33. C. Gonçalves, T. Dinis, and T. M. Batista, Phytochemistry 66, 89 (2005). doi:10.1016/j.phytochem.2004.10.025 